\title{
Teaching English Tenses to EFL Learners: Deductive or Inductive?
}

\author{
I Ketut Trika Adi Ana, Ni Made Ratminingsih \\ STKIP AH Singaraja, Ganesha University of Education Singaraja, Bali-Indonesia
}

\begin{abstract}
English tenses are one of the major problems for Indonesian learners in learning English. Therefore, an appropriate teaching strategy to help the learners in understanding those English tenses is urgently needed. For that reason, this article aims at introducing an innovative strategy for teaching English tenses for adult learners. This innovative strategy combines deductive and inductive approaches. It starts with deductive approach and then will be followed by inductive approach. The deductive approach is applied in order to make the learners remember the rules of English tenses, while the inductive approach is conducted to make the learners understand and able to use them communicatively.
\end{abstract}

\section{Introduction}

Grammar is an essential component that should be learnt in order to master a language. If one uses incorrect grammatical pattern in constructing a sentence, there is a tendency that the sentence will constitute different meaning from what it is intended, or even meaningless. Therefore, grammar is called as "sentence-making machine" by Thornbury [12]. It means that, even though one has sufficient number of vocabulary, without having good grammar mastery, he will find problem in arranging those vocabularies into good sentences. As what is said by Ur [13], one cannot use words unless he/she knows how those words should be put. Considering the significant role of grammar in mastering a language, grammar is important to be learnt by the learners of the language. Thus, language teachers need to teach grammar to their learners. In general, there are two approaches in teaching grammar, inductive and deductive approaches [10]. According to Brown [3] and Thornbury [12], both inductive approach and deductive approach have their strengths. The strengths of deductive approach are: (1) this approach is straight forward, so that it will not waste too much time for explanation. It gives more opportunities for learners to apply the rules; (2) it respects the intelligence and maturation, especially for adult learners; (3) it confirms many learners' expectation, especially for those who want to have an analytical learning style. On the other hand, inductive approach is good for some reasons: (1) it will help the learners, especially young learners, who cannot understand the abstract concept of grammar, to learn grammar unconsciously; (2) it will make the learners become autonomous learners; (3) it will make grammar learning more meaningful; and (4) it will make the learners become more active in teaching and learning process. Moreover, deductive approach will be more appropriate to be applied for adult learners, while inductive approach will be better for teaching young learners [3]. It is obvious since young learners usually do not like a serious circumstance. They love to play and only have a short span of concentration.

Conversely, adult learners may take benefit from deductive approach, because they can make use of abstract things to gain knowledge. They can get involved in a serious circumstance and can concentrate longer than young learners [3], [4], [12]. Ellis [5] believes that language teachers should teach forms that differ from the learners' first language. Hence, this article aims at introducing an innovative strategy to teach the 16 English tenses, which are considered different from Indonesian grammar system and difficult to be understood by the learners. Based on the strengths of deductive and inductive approaches, an innovative teaching strategy which combines both deductive and inductive approach is proposed. Combining deductive and inductive approach has been done by Nunan [10]. He argues that combining deductive and inductive approach for teaching grammar will be good especially in focusing a certain purpose of grammar teaching. In addition, by combining both deductive and inductive approaches because it is expected that the learners are not only able to remember or understand the English tenses, but also able to use it communicatively.

\section{Innovation in Education}

Innovation is an idea, goods, event, or method that is felt or observed to be a new thing for someone or some people (society), both as a result of invention or discovery. Invention is a human creation that is purely new, or does not exist before, while discovery is a creation of something which has already existed, but its existence has never been realized [11]. The strategy that is introduced in this article is considered as an innovative strategy since it combines deductive and inductive approach. In addition, during the deductive approach process there is a new formula that was invented by the writers that can be used to find out all of the English tenses patterns based on five basic patterns. 


\section{Young vs. Adult learners}

Generally, learners can be divided into three categories based on their age, namely young learners, adolescence, and adult learners. Young learners are those whose ages are between 2 and 14 year old, adolescents are those whose are around 12 to 17 year old, while adult are commonly 16 year old and above [7]. From teaching English as foreign language point of view, young learners are those who learn English as a foreign language for the first six or seven year of the formal school system that is usually in the

elementary school level [9]. Seeing from their age, they are about 5 until 12 year old. Age is one of the major factors that should be taken into account in deciding how to teach the learners. It is because learners with different age will have different characteristics. Young learners do not only focus on what is being taught, but they also learn something else at the same time, such as acquiring information from their surroundings.

Moreover, young learners may consider seeing, hearing, and touching are as important as the teacher' explanation. They usually respond the activities focusing their life and experience well. They can be good speakers of new a language if they have sufficient facilities and enough exposure of the target language [7]. They may learn foreign language better through a game. Young learners love to play and learn best when they enjoy themselves. Adult learners have mature personality, many years of educational training, a developed intelligence, a determination to get what they want, fairly clear aims, and above all strong motivation to make as rapid progress as possible. An adult is no longer constrained by the educational system or parental pressure to learn English, so the problems of dealing with conscripts do not exist. In addition, adult learners can decide about what they want to learn, but young learners cannot and adult learners may learn best by enabling their abstract thinking. Taking into consideration, the different characteristics between young and adult learners, teachers should select strategies of teaching which suit different ages. Young learners should be taught by applying teaching strategies which are suitable for young learners and vice versa. It is important to be done in order to make the learners achieve an optimum result of their study, since a proper teaching strategy will bring positive effect toward the outcome of the teaching and learning process.

\section{Deductive vs. Inductive Approach}

Teaching English Tenses can be done through deductive and inductive approach. Both of the approaches have their own strengths and weaknesses. Deductive approach starts with the presentation and explanation of the rules, and then it is followed by the examples of the sentences using the rules. On the other hand, an inductive approach starts with examples from which a rule is inferred. In other words, in deductive approach the teachers directly explain the rules of the English tense. The explanation is completed with discrete sentences, and it is followed with samples of sentences by the learners to confirm their understanding. If the teachers apply inductive approach, they do not give the rule directly to the learners, they just give list of sentences and from the sentences they ask the learners to discover the rule by analyzing the provided sentences in a discourse level. It is just like acquiring the first language, in which parents do not introduce the rules of the first language but because it is practiced everyday and continuously with many exposure then the grammatical rules of the first language are acquired naturally and effortlessly. The benefits of deductive approach for teaching English grammar are: (1) it is straight forward, therefore, it is time-saving; (2) it respects the learners' intelligence and maturity, especially for adult learners; (3) it confirms many learners' expectation about classroom learning, especially for those who have analytical learning style; (4) it allows the teacher to deal with language points as they come up rather than having to anticipate them and prepare them in advance. While the benefits of inductive approach are: (1) inductive approach will make the rules more meaningful and memorable; (2) the mental effort that is done by the students will ensure their cognitive depth; (3) students are more actively involved during the teaching and learning process compared to applying deductive approach; (4) this approach may satisfy the desire of the students who has good ability in pattern recognizing and problem solving; (5) this approach prepares the learners to be an active or selfassisted learners [8].

Besides, those benefits above, both deductive and inductive approaches also have weaknesses. The weaknesses of deductive approach for teaching English grammar are: (1) this approach may be difficult for some learners, especially for young learners since they do not have enough metalanguage or they cannot understand the abstract concept; (2) teacher's explanation that dominates the teaching and learning process may decrease the learners' interaction, therefore the learners may become passive learners; (3) teacher' explanation is seldom remembered by the learners, compared to other form of demonstrations. While, the weaknesses of inductive approach are: (1) it may take a longer time until the learners could discover the rule compared to teaching using deductive approach; (2) the time and energy spent in working out the rules may mislead the learners that their main objective of studying the language is mastering the rules not the meaning; (3) learners my hypothesize the wrong rule, or their 
understanding may be to broad or narrow from what it is expected; (4) it may make the learners who accustom with deductive approach become frustrated, since they may expect to be given the rules directly [12]. In regard to the strengths and weaknesses of both approaches, the writers propose to integrate the implementation of the two rather than to select each of them. The writers design a teaching strategy that maximizes the strengths of the two approaches to be applied for teaching English tense rules to adult learners, which it starts with deductive approach and then followed by inductive approach. The writers combine the two approach because in the first phase of learning comprehension is the most important thing, especially for adult learners as they can utilize their abstract thinking to construct their knowledge of the target language. After they have a strong ground about the concept of the English tense rules, the inductive approach can be carried out to intensify their understanding through a maximum application of the rule in a discourse level. 5 . Innovative Strategy to Teach English Tenses for Adult EFL Learners This strategy will start with deductive approach and then will be continued with inductive approach.

It consists of four steps, namely: (1) understanding the 5 basic rules of English tenses; (2) discovering other English tense rules based on the 5 basic rules; and (3) understanding the discovered tense rules; and (4) creating communicative activity to apply the 16 rules. The first step is done in order to make the learners understand and memorize the 5 basic rules of English tenses. The first step will be a teachercentered activity. The second step aims at generating the knowledge that the learners already had to help them memorize the 16 English tenses. It will be a learners-centered process since they will trace other tense rules themselves or cooperatively with other learners. On the third step of the teaching activity, teacher will give guidance for the learners in understanding all of those 16 tenses. The teacher will not directly explain how to use those tense rules, but he will ask the learners to discuss it in a group. He will be a facilitator so that the discussion runs effectively. The fourth step is creating a communicative activity that will guide the learners to internalize the tense rules, so that they can use them communicatively. However, it should be kept in mind that there is no such strategy that can be applied for any learners in any circumstance or situation [8].

\section{The Steps in applying Innovative Strategy to Teach English Tenses for Adult EFL Learners}

As what has been mentioned above, the proposed strategy consists of four steps. The two first steps will be done deductively, while the next two steps will be conducted inductively (see Figure 1 and
Figure 2). However, it should be kept in mind that those four steps cannot be done in one class session. Those steps should be done in several class sessions. The followings are brief explanations about those four steps.

\subsection{Understanding the 5 Basic Rules (BR) of English Tenses (deductive and teacher centered)}

The first activity that should be done in applying this strategy is making the learners remember and understand the $5 \mathrm{BR}$ of English tenses (see Table 1). Those $5 \mathrm{BR}$ are simple present tense, simple past tense, simple future tense, continuous tense, and perfect tense. Besides those rules, it is also important to teach the learners about the transformation of auxiliary verb (be, has/have, shall/will) into their past and past participle form (see Table 2). Since this first activity is done in order to build or refresh the prior knowledge of the learners, so that they can use it to do the next activity, this first activity is a teacher centered activity. According to Westwood [10], teacher-centered activity (direct approach) will be essential for delivering key concept(s) that enables the learners to explore more profound knowledge themselves. In this strategy, it is done by presenting those tense rules to the learners and then asking them to create some sentences using those rules.

Table 1. Basic Rules (BR)

\begin{tabular}{|l|l|l|l|l|}
\hline No & \multicolumn{1}{|c|}{$\begin{array}{c}\text { Name of the } \\
\text { formula }\end{array}$} & \multicolumn{3}{|c|}{ Formula } \\
\hline 1. & Present Tense & S & VI* & \\
\hline 2. & Past Tense & S & VII & \\
\hline 3. & Future Tense & S & Will/Shall & VI \\
\hline 4. & Continuous Tense & be & V-ing \\
\hline 5. & Perfect Tense & \multicolumn{2}{|l|}{ has/have } & VIII \\
\hline
\end{tabular}

*note: It should be explained further during the

"Understanding the Discovered Tense Rules" step.

Table 2. Transformation of be, has/have, shall/will

\begin{tabular}{|l|l|l|l|l|}
\hline No & Auxiliary & \multicolumn{1}{c|}{ VI } & \multicolumn{1}{c|}{ VII } & \multicolumn{1}{c|}{ VIII } \\
\hline 1. & Be & is, am, are & was, were & Been \\
\hline 2. & Has/have & has/have* & Had & Had \\
\hline 3. & Shall/will & shall/will* & Would & Would \\
\hline
\end{tabular}

*note: It should be explained further during the

"Understanding the Discovered Tense Rules" step.

\subsection{Discovering other English Tense Rules based on the 5 BR (deductive, cooperative, and learners centered)}

The second step is done by asking the learners to use their prior knowledge, the $5 \mathrm{BR}$, to generate the other 11 English tense rules. To do this, the teacher 
should tell the learners about the steps to find the other English tense rules based on the 5 BR. Those steps are:

1) The basic rules are written based on the name of the tense that is going to be found. For example, if the English tense that is going to be found is "Present Continuous Tense", then the needed BRs are "Present Tense" and "Continuous Tense".

2) The name of the tense that is going to be found should be organized respectively. For instance, the rule that is going to be found is "Present Continuous Tense", so the "Present Continuous" rule should be placed on the top and then followed by the "Continuous Tense" rule.

3) The later rule is written below the verb of the preceding rule. This criterion is very important. To find the other rules from the BR, the later rule should be placed under the verb of the previous rule. If there are three BRs are used, for example in finding out the rule of "Present Perfect Continuous Tense". The "Present Tense" rule is paced on the top, The "Perfect Tense" rule is placed under the verb of "Present Tense" rule, while the "Continuous Tense" rule is placed under the verb of "Perfect Tense" rule. 4) The subject (S) in the later rule should be omitted. In an English tense rule, there is only one subject needed. Therefore, the subject of the later rule should be omitted to avoid confusion.

5) Do substitution from the organized basic rules vertically. When the BRs are organized systematically based on the type of English tense that is going to be found, then do substitution to form the new rule.

The application of the $5 \mathrm{BR}$ to find other English tense rules can be seen on example 1 , example 2 , and example 3.

Example 1

The steps in finding the rule of "Present Continuous Tense"

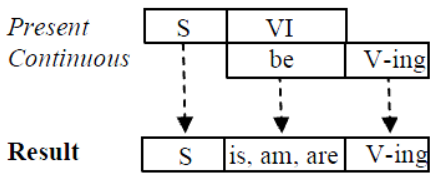

Example 2

The steps in finding the rule of "Present Perfect Tense"

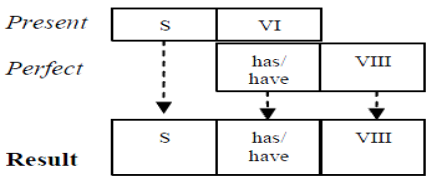

Example 3

The steps in finding the rule of "Present Perfect Continuous Tense"

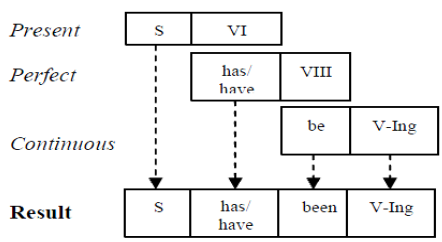

*note: In finding out the "Perfect Continuous Tense Rules" there will be three $B R$ are involved. It should be kept in mind that the later rule should be placed under the verb of the former rule. Therefore, the third rule should be placed under the verb of the second rule.

During this step, the learners are asked to find the positive sentence rules only. This is done in order to keep the learners feel that studying English tense is easy. The negative and interrogative form will be discussed in the next step with inductive approach. This is done in order to build a new paradigm in the learners' mind that English tense is easy. If they feel that English tenses are easy, it will reduce their affective filter and their anxiety so that they can learn it in more comfortable situation. This activity is continued by giving a chance for the learners to create some sentences based on the rules that they have found themselves.

This second step can be done individually by the learners, but it is suggested that they do it in pairs or small groups (groups of 3-4 learners) or cooperatively. It is very important because it will help slow learners to learn from their partner or group members (peer teaching). This activity will help the learners to form their own knowledge. If they can form their own knowledge, it will last longer than if they gain the knowledge from the teacher's explanation [14]. Since this activity is mostly done by the learners independently, it means that this activity is a learners-centered activity. Learners-centered activity is good when the aim of the instruction is activating the learners in acquiring knowledge, skills, and strategies [14]. To make it more fun, the teacher may make it into a competition, in which the fastest group, or the group that can formulate the other 11 English tense rules from the $5 \mathrm{BR}$ sooner that the other group will be the champion.

\subsection{Understanding the Discovered Tense Rules (inductive, cooperative, and learners centered)}

The third step is done grouping the learners into small groups that consist of 3-4 learners. Each group 
receives a text in which in that text there are several sentences which are written by following a particular English tense rule. For example, if the teachers are going to build the learners' understanding about "Simple Past Tense" he/she should provide the learners with some sentences which are written in "Simple Past Tense" rule. To help the learners in understanding about when the rule should be used, the sentences can be arranged in the form of recount text.

\section{Sample of the text:}

Holiday in Bali Island Last month, Anna went to Bali Island to enjoy her holiday. She went there with her family. They took a plane to get there. Anna was very happy because she visited one of the most beautiful islands in the world. She visited many tourism objects there, such as Kuta Beach, Ubud, and Kimtamani. Since Bali Island is also famous of its traditional arts, she also enjoyed some traditional dances there. She had an opportunity to watch two of the most famous Balinese dances, those were Kecak and Barong dances. In addition, they also bought some handicrafts as souvenirs. They stayed there for two weeks before they finally went back to America.

Then, each group is asked to discuss those sentences in order to find out the meaning of the sentences and the rule that is used to create those sentences. They have to guess it by tracing the rules based on the sentences which are provided. By doing this the learners indirectly will construct their understanding about when they have to use the tense rule.

After they have discovered the rule and understand the meaning of each sentence and know when they have to use that tense rule, teacher may start to give questions which are related to the content of the text. However, the questions should be made based on the same English tense rule as in the text.

Sample of the questions:

1) Did Anna go to Bali Island last month?

2) Did they go to many tourism objects?

3) Did she go to Bali Island alone?

4) Did she go to Bali for attending a conference?

5) Did she enjoy her time in Bali?

After the learners receive the questions, teacher guides the students to answer the questions. This kind of activity will lead the learners to understand the interrogative and negative pattern of the English tense rule that is being learnt. If necessary, teacher may also ask the learners to do a discussion in order to analyze and discover the pattern of the interrogative and negative forms of the tense rule.
Sample of the answers

1) "Yes, she did" or "Yes, she went to Bali

Island last month.

2) "Yes, they did" or "Yes, they went to many tourism objects"

3) "No, she did not" or "No, she did not go to Bali Island alone"

4) "No, she did not" or "No, She did not go to Bali Island for attending conference"

5) "Yes, she did" or "Yes she enjoyed her time in Bali"

During the discussion and the reporting activities, the teacher should place himself/herself as a facilitator. During the discussion, the teacher may move to one group to another group to assist the learners, especially the one who still has problem. The teacher also should clarify and explain if there is a mistake or error that is made by the learner in the result of their discussion.

This third step aims at helping the learners to understand the tense rules that they have found, especially about when they have to use it. In addition, this activity also will indirectly guide them to understand how to create negative and positive form. Since knowing the right time for using the English tense rules and the negative and positive form of those rules, this step will make the rules that they have found become meaningful. Therefore, this step will be a very crucial step.

\subsection{Creating Communicative Activity to Apply the 16 Rules (inductive, communicative)}

Communicative activity here is defined as an activity in which the learners have an opportunity to use the target language for an authentic communication. Since the strategy that is introduced in this paper is for teaching English tense rules, the target language here refers to English. The aim of this activity is to make the learners able to apply their knowledge about the 16 English tense rules communicatively. Therefore, this forth activity is done by doing a role play. To make the role play runs effectively, before starting the role play, teacher should decide the situation and the learners' role. For instance, if the teacher wants to emphasize on the use of past tense, he can ask the learners to act like a reporter who is reporting news. By doing this, the teacher will be able to see whether or not the learners have mastered the past tense rule. In other word, it will make the learners aware of the kinds of tense that they are focusing on. Since this step is conducted inductively, if the learners make an error, teacher should guide the learners to revise it inductively and implicitly. Teacher can do it by giving implicit examples. During this step, he should avoid direct explanation 
toward the errors made by the learners. It is done in order to avoid the learners from feeling guilty. If the learners feel guilty, it will decrease their confidence which results on the possibility of being passive students.

\section{The Benefits and Problems in Implementing this Innovative Strategy}

Each teaching strategy has its own strengths and benefits. Based on the writers' experience in implementing this strategy for teaching English tense there are some benefits and problems in implementing it. In order to be able to implement this strategy well, teachers who are going to apply this strategy should know the benefits and the problems that they may find during the implementation of this strategy. By knowing the benefits and the problems, teachers will be able to adjust this strategy based on the situation that is faced by the teacher. The benefits of implementing this strategy are:

a. It will help the learners to memorize the 16 English tense rules just by understanding 5 basic rules of English tenses. It means that the learners do not need to force themselves to memorize the 16 English tense rules separately. They just need to understand the 5 basic rules and then discovery the other rules from the 5 basic rules.

b. It is really suitable for the adult EFL learners. Since the cognitive ability of the adult learners has been developed and they can understand abstract knowledge, this strategy is appropriate for adult learners.

c. The combination of the deductive and inductive approach makes the instruction process moves from a teacher-centered activity to the learnerscentered activity. In other words, it can be said that this strategy trains the learners to be an independent learner. However, before they are ready to be independent learners, this strategy makes sure that the learners have sufficient knowledge as the basis for developing their knowledge individually. It is really important to make the learners become independent learners, because a good learner is the one who does not stop learning.

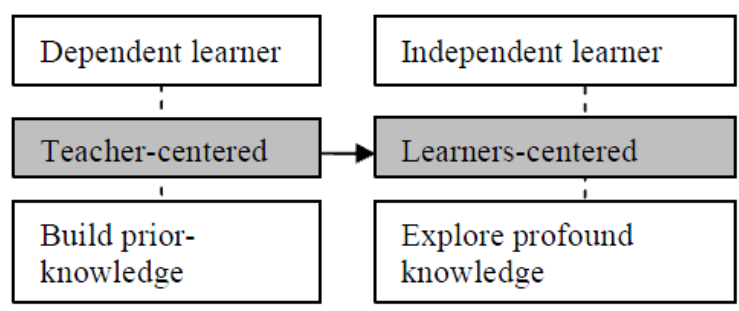

Figure 1. The role of Teacher-centered Activity and Learners-centered Activity in the proposed Strategy d. This strategy makes the learners not only able to memorize the rules of the English tenses, but they will also able to understand and apply the rules. Figure 2 shows that there are four major steps in this strategy. The first and second steps are aimed at memorizing the 16 English tense rules. It starts by understanding the $5 \mathrm{BR}$, and followed by finding out the other English tense rules from the $5 \mathrm{BR}$. The third step is conducted for understanding when those 16 English tense rules should be used. While the fourth or the last step is done for applying the 16 English tense rules that have been found and understood.

Therefore, after having an English course which is conducted through this teaching strategy the EFL learners will not only able to memorize the English tense patterns, but they will also be able to understand and apply them. In other words, by applying this strategy during teaching English tenses to the adult EFL learners, the

three cognitive dimensions they are: (1) to remember, (2) to understand, and (3) to apply will be achieved automatically at the end of the course [1]. The steps and the aim of each step in this innovative teaching strategy can be seen on Figure 2 .

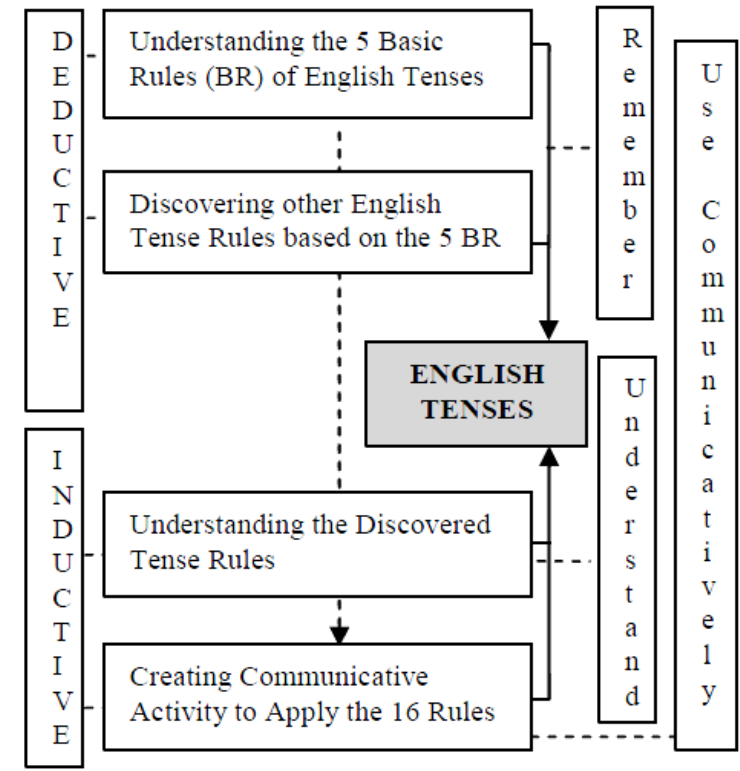

Figure 2. The Design of Innovative Strategy to Teach English Tenses for Adult EFL Learners

While the problems that may be faced by the English teacher in implementing this strategy are:

a. English tense rules are not the only material that should be mastered. English tenses rules are very important for mastering English. However, teaching English covers more than just English tense rules. Usually, English tense rules are not considered as the major material since the teaching and learning process are conducted through skills-based process, 
in which English tenses are indirectly inserted in those skills.

b. The learners should have prior knowledge about English tense rule. To make this teaching strategy runs smoothly, the learners should have learnt English before. It is because, to do the first and the second steps of this strategy, the learners should know about English tense in general.

c. It is time consuming. To conduct the four steps of this strategy requires many meetings. It is because this strategy is a combination of deductive and inductive approach. The first and the second steps can be conducted in few meetings, since these steps are conducted deductively and only focusing on memorizing the English tense rules. However, the third and the forth meeting may need more meetings. It is because the third and the fourth steps are conducted inductively. The third step is conducted for understanding the 16 English tense rules by analyzing examples and the fourth step is conducted to make sure that the learners can apply their understanding about the English tense rules correctly.

d. The high achiever learners may get bored. Since this strategy consists of four steps and the four steps are only concerning on English tense, the high achiever learners who have mastered the English tense rules may get bored during the teaching and learning process. It is because they will find it too easy.

\section{Conclusion}

EFL teachers should not merely teach their learners to be able to remember the grammatical rules of English, but more importantly they also have to guide the learners to understand those rules and make them able to use those rules communicatively. Since adult EFL learners have their capability to use their abstract way of thinking, EFL teachers can start building the adult EFL learners' knowledge about the grammatical rules of English through deductive approach, and then gradually guide them to make them accustomed with those rules and make them able to use it communicatively through inductive approach. By combining deductive and inductive approaches, it is expected that the learners will master English tense rules comprehensively and become an independent learners.

However, it should be kept in mind that there is no teaching strategy without any weaknesses. For that reason, teacher should equip themselves with various teaching strategies. In addition, they also should know about the strengths and the weaknesses of each strategy in order to be able to select an appropriate teaching strategy for different situation, and could anticipate the problems that may be found during the application of the strategy.

\section{References}

[1] Anderson, L. W., D. R. Krathwohl, P. W. Airasian, K. A. Cruikshank, R. E. Mayer, P. R. Pintrich, J. Raths, M. C. Wittrock. A Taxonomy for Learning, Teaching, and Assessing: A Revision of Bloom's Taxonomy of Educational Objectives. Longman, Inc, New York, 2001.

[2] Broughton G., C. Brumfit, R. Flavell, P. Hil, and A. Pincas, Teaching English as Foreign Language. Routledge, United States of America, 2003.

[3] Brown H.D., Principles of Teaching and Learning Language. Pearson Education, White Plains, 2007.

[4] Cameroon L., Teaching Languages to Young Learners, Cambridge University Press, United Kingdom, 2001.

[5] R. Ellis, Current Issues in the Teaching of Grammar: An SLA Perspective, Tesol Quarterly Vol. 40, No.1, Teachers of English to Speakers of Other Languages, Inc. 2006, pp. 88.

[6] Gerngross G., H. Puchta, and S. Thonbury. Teaching Grammar Creatively. Helbling Languages, Athesia, 2007.

[7] Harmer, J. How to Teach English: An Introduction to the Practice of English Language Teaching. Essex, Pearson Education Limited, 2007.

[8] Hinkel E., and S. Fotos, New Perspective on Grammar Teaching in Second Language Learning. Lawrence Erlbaum Associates, Inc, United States of America, 2002.

[9] McKay, P. Assessing Young Language Learners. Cambridge, Cambridge University Press, 2007.

[10] Nunan, D., Practical English Language Teaching, McGraw-Hill, New York, 2003.

[11] Sa'ud, U. S. Inovasi Pendidikan. Bandung: Alfabeta, 2010.

[12] Thornbury, S., How to Teach Grammar. Pearson Education Limited, Malaysia, 2002. [13] Ur, P., Grammar Practice Activities: A Practical Guide for Teacher, Cambridge University Press, Cambridge, 2006.

[14] Westwood, P., What Teachers Need to Know about Teaching Methods, Camberweel, Vic, Australia, 2008. 